\title{
Development of Hard Secondary Cooling by High-pressure Water Spray in Continuous Casting
}

\author{
Yoichi ITO, ${ }^{1)}$ Takeshi MURAI, ${ }^{2 l}$ Yuji MIKI, ${ }^{2)}$ Masayuki MITSUZONO ${ }^{3)}$ and Takatoshi GOTO ${ }^{4)}$ \\ 1) Steelmaking Research Dept., Steel Research Laboratory, JFE Steel Corporation, Kawasakidori 1-chome, Mizushima, \\ Kurashiki, 712-8511 Japan. E-mail: yo-ito@jfe-steel.co.jp $\quad$ 2) Steelmaking Research Dept., Steel Research Laboratory, \\ JFE Steel Corporation, 1, Kokan-cho, Fukuyama, 721-8510 Japan. $\quad 3$ 3) Steelmaking Dept., West Japan Works (Kurashiki), \\ JFE Steel Corporation, Kawasakidori 1-chome, Mizushima, Kurashiki, 712-8511 Japan. 4) Control Engineering Dept., \\ West Japan Works (Kurashiki), JFE Steel Corporation, Kawasakidori 1-chome, Mizushima, Kurashiki, 712-8511 Japan.
}

(Received on March 30, 2011; accepted on May 17, 2011)

\begin{abstract}
Cooling intensity in secondary cooling is an important factor for achieving high-speed casting. In this study, we investigated the effects of the hydraulic pressure and water flow rate of a cooling water spray on cooling intensity, and developed a more efficient secondary cooling system with a high-water pressure spray. In laboratory experiments, a test plate was heated to $1273 \mathrm{~K}$ and then cooled below a certain temperature by one nozzle under various experimental conditions. The heat transfer coefficient was estimated using the temperature data from thermocouples $3 \mathrm{~mm}$ below the cooled surface. The average heat transfer coefficient with a hydraulic pressure of $5 \mathrm{MPa}$ was 2.8 times larger than that of a conventional water spray nozzle at the same water flow rate. On the basis of the laboratory results, plant trials were carried in the Kurashiki No. 2 CCM at JFE West Japan Works. A high-pressure water supplying device (maximum $5 \mathrm{MPa}$ ) with high pressure type nozzles was installed in one segment at a position from 2.5 to $4.0 \mathrm{~m}$ below the meniscus and the water flow rate of the high-pressure spray was the same as that of the conventional one. It was confirmed that casting speed was increased by $30 \%$ without any inner cracks or surface cracks for several steel grades. In addition, the measurements of slab surface temperature were in good agreement with the thermal calculation results from the laboratory heat transfer coefficient data.
\end{abstract}

KEY WORDS: continuous casting; secondary cooling; water spray; heat transfer coefficient; hydraulic pressure; intensive cooling.

\section{Introduction}

To meet the demand for higher product quality and productivity in the steelmaking process, more efficient spray cooling systems for continuous casting are needed. Control of cooling rate, transformation, and precipitates during the solidification process will be required as a function of secondary cooling in the future, so a new cooling system for intensive cooling that is different from the present conventional spray cooling needs to be developed.

Secondary cooling plays an important role in preventing the occurrence of surface and inner cracks. In order to raise the productivity of continuous casting, it is desirable to achieve intensive cooling to avoid the ductile temperature during bending and straightening and to keep the inner strain below the critical value for inner cracks. As one example, JFE Steel Corporation has developed a high-speed casting technology based on high-efficiency air-mist spray which achieves a casting velocity of $3.0 \mathrm{~m} / \mathrm{min}$ in slab casting. ${ }^{1)}$

Many reports have been published regarding air-mist sprays, ${ }^{2,3,5,6)}$ such as the influence of mist diameter, ${ }^{2)}$ Leidenfrost effect, ${ }^{3,4)}$ water flow density, impact pressure, ${ }^{5)}$ etc. on cooling intensity. Some researchers have proposed empirical correlations to predict the spray heat transfer coefficient from the water flow rate and the surface temperature through spray cooling tests. ${ }^{6-8)}$ Nozaki et al. ${ }^{9)}$ introduced an empirical adjustment coefficient to the previous correlation ${ }^{7)}$ based on in-plant temperature measurements at the straightening point.

Barber et al. ${ }^{10)}$ measured the surface temperature in the casting direction of a slab using thermocouples embedded in the strand. The contributions of roll cooling, spray cooling and indirect cooling to the heat transfer in the secondary cooling zone were analyzed. Mathematical models that take these factors into account have been used to optimize secondary cooling.

In the work of Raudensky, ${ }^{3)}$ the influence of the water and air pressures of the spray on the Leidenfrost temperature was investigated. Heat transfer coefficient was changed ten times when the temperature crossed the Leidenfrost temperature demonstrating the importance of controlling the water and air pressures to ensure uniform cooling.

In contrast, there have been few reports on water spray and high-pressure water jets ${ }^{11,12)}$ and the effects of the hydraulic pressure above $1 \mathrm{MPa}$ and water flow rate of the cooling water spray on cooling intensity are not known.

In this study, the effects of the hydraulic pressure and 
water flow rate of a cooling water spray on cooling intensity were investigated through laboratory experiments and plant trials.

\section{Concept of a New Cooling System for Intensive Cool- ing}

\subsection{Position of Intensive Cooling}

To improve the productivity of the continuous caster, it is efficient to increase the machine length and to add an intensive cooling zone, but revamping the machine would require enormous costs and many days. The aim of this study was to quantitatively evaluate intensive cooling using a new cooling device developed for existing cooling zones. The influence of the position of the intensive cooling zone on the shortness of metallurgical length calculated by a mathematical model is shown in Fig. 1. The calculation conditions were a casting velocity of $1.0 \mathrm{~m} / \mathrm{min}$ at the Kurashiki No. 2 continuous slab caster. A heat transfer coefficient of 1000 $\mathrm{kcal} / \mathrm{m}^{2} / \mathrm{h} / \mathrm{K}$ was assumed for the intensive cooling zone. It is obvious that installing the intensive cooling device in the No. 3 or No. 4 cooling zone is the most effective for shortness of metallurgical length. Based on this result, we decided to develop intensive cooling for the No. 3 cooling zone.

\subsection{Method of Intensive Cooling}

To increase the cooling ability in secondary cooling, it is important to improve the following factors:

- Enlargement of cooling area in the casting direction.

- Improvement of heat transfer for the film boiling regime on a cooling curve.

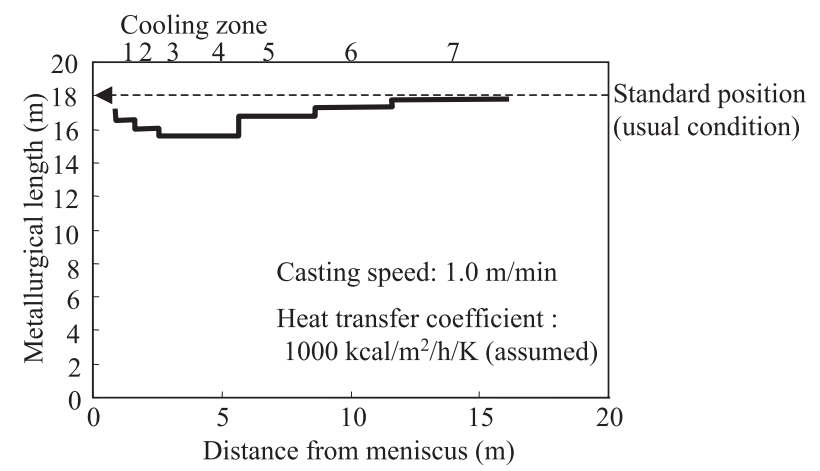

Fig. 1. Relation between metallurgical length and intensive cooling zone.

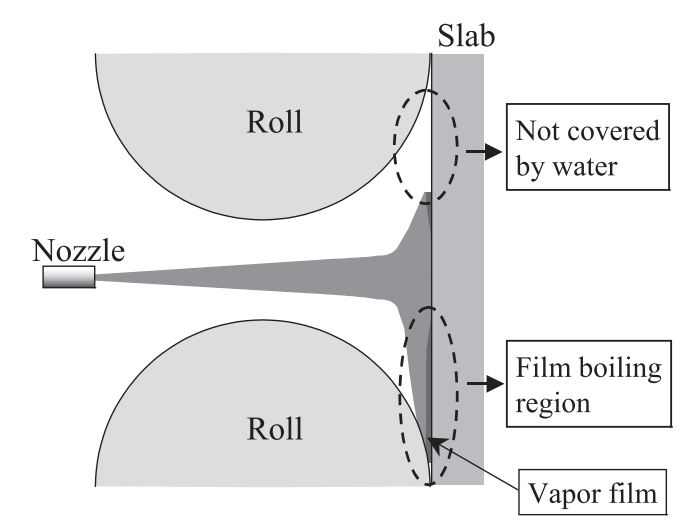

Fig. 2. Schematic view of secondary cooling in continuous casting.
Figure 2 illustrates the situation of secondary cooling between rolls. It is well known that there is a regime covered by atmospheric air (air cooling zone) below the upper roll and indirect cooling zone between the direct cooling zone by spray jet and the lower roll. ${ }^{13)}$

A schematic diagram of the heat transfer curve is shown in Fig. 3. The spray heat transfer curve has four regions: ${ }^{14)}$ no boiling, nucleate boiling, transition boiling, and film boiling. The slab surface temperature range of 1073-1273 $\mathrm{K}$ is considered to be the most important factor in secondary cooling for preventing internal cracks in slabs and achieving intensive cooling. In this temperature region, the heat flux exhibits a minimum at the Leidenfrost point. At high surface temperatures where film boiling is dominant, a vapor film adjacent to the solid hot surface prevents or minimizes direct droplet contact with the surface, resulting in a low heat transfer rate. It is essential to increase the heat flux in this region to raise productivity in continuous casting.

One way to achieve this is a new cooling system using a high-pressure water spray, as reported in a previous study. It was difficult to reduce the distance between the slab and spray due to restrictions on the equipment to allow water to reach bellow the upper roll and destroy the vapor film. This study used a high-pressure water spray as an intensive cooling device.

\section{Laboratory Tests}

\subsection{Specifications of the Spray}

The specifications of the conventional spray equipped in the No. 3 cooling zone at Kurashiki No. 2 CCM and the newly developed high-pressure water spray are shown in Table 1. The conventional spray uses a flat spray with a water pressure of $0.7 \mathrm{MPa}$ and spray angle of 110 degrees.

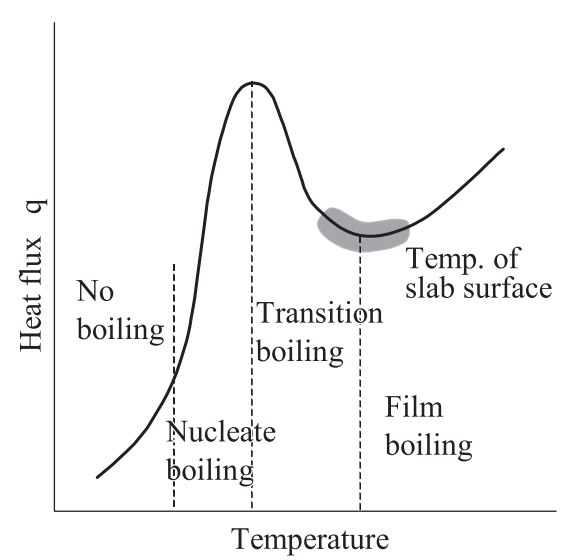

Fig. 3. Relation between heat flux and surface temperature of slab.

Table 1. Specifications of the nozzles.

\begin{tabular}{lcc}
\hline \multicolumn{1}{c}{ Symbol } & Nozzle A & Nozzle B \\
\hline Nozzle type & Conventional type (flat spray) & High-pressure type \\
Spray angle (width) & $110 \mathrm{deg}$. & $50 \mathrm{deg}$. \\
Spray height & $360 \mathrm{~mm}$ & $335 \mathrm{~mm}$ \\
Max. back pressure & $0.7 \mathrm{MPa}$ & $5 \mathrm{MPa}$ \\
Max. water flow rate & $16\left(\mathrm{~m}^{3} / \mathrm{h}\right) / \mathrm{m}^{2}$ & $16\left(\mathrm{~m}^{3} / \mathrm{h}\right) / \mathrm{m}^{2}$ \\
\hline
\end{tabular}


The maximum water pressure of the high-pressure water spray is $5 \mathrm{MPa}$ and the spray angle is 50 degrees. The water flow rate of the high-pressure water spray at the maximum water pressure of $5 \mathrm{MPa}$ is the same as that of the conventional spray of $0.7 \mathrm{MPa}$.

\subsection{Measurement of Heat Transfer Coefficient}

To evaluate the cooling intensity for these two sprays, the heat transfer coefficient during spray cooling was measured by laboratory experiments. Figure $\mathbf{4}$ shows a cross-sectional view of the test piece, which was a stainless steel plate of dimensions $500 \times 500 \times 50 \mathrm{~mm}$. The plate, which had 26 thermocouples embedded at a depth of $3.0 \mathrm{~mm}$, was heated to a particular temperature in an inert gas atmosphere. Figure 5 shows the experimental procedure, which consisted of the following steps:

- The test plate is heated in the furnace to around $1273 \mathrm{~K}$.

- The plate is moved from the furnace to a certain location and raised in the vertical direction.

- Spray cooling is started by switching on the pump.

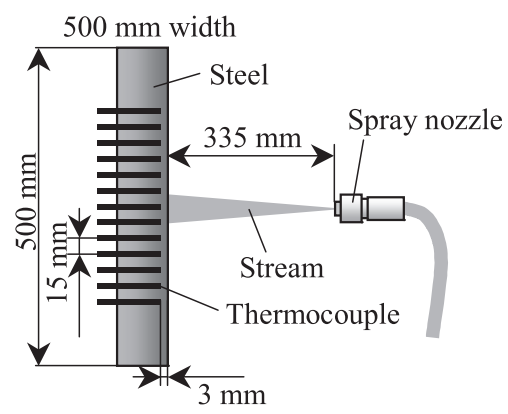

Fig. 4. Cross-sectional view of test piece.
- Spray cooling is stopped after the plate temperature falls to around $673 \mathrm{~K}$ by switching off the pump.

- The heat transfer coefficient is evaluated by thermal calculation using temperature data collected at a specified rate (10 readings/sec).

The main test results are plotted in Figs. 6 and 7. It can be seen that the heat transfer coefficient of the high-pressure water spray (spray B) was much larger than that of the conventional spray (spray A) at the same water flow rate. The heat transfer coefficient below the upper roll for spray $\mathrm{B}$ was $300 \mathrm{kcal} / \mathrm{m}^{2} / \mathrm{h} / \mathrm{K}$ at $1173 \mathrm{~K}$. The reason why the test piece is raised in the vertical direction is to consider the influence of the no-water zone below the upper roll and the water which collects on the lower roll. The average heat transfer coefficient between the upper roll and lower roll is shown in Fig. 8. At the hydraulic pressure of $5 \mathrm{MPa}$, the average heat transfer coefficient was 2.8 times larger than that of the conventional water spray nozzle at the same water flow rate.

\subsection{Observation of Water Distribution}

The maximum achieved distance of the water stream in the vertical direction and the stream extension in the horizontal direction were investigated. The experimental device was made from acrylic resin with a transparent roll and strand, and the achieved distance was measured in the opposite direction. Figure 9 shows a schematic view of the apparatus for measuring stream extension, and Fig. 10 shows the relationship between the achieved distance of the stream and the back pressure when using nozzle B. The achieved distance showed a linear correlation with back pressure. It is thought that no-water zones can be completely eliminated by using a high-pressure water spray of more than $2.5 \mathrm{MPa}$ in secondary cooling when the roll pitch is $300 \mathrm{~mm}$ or less.

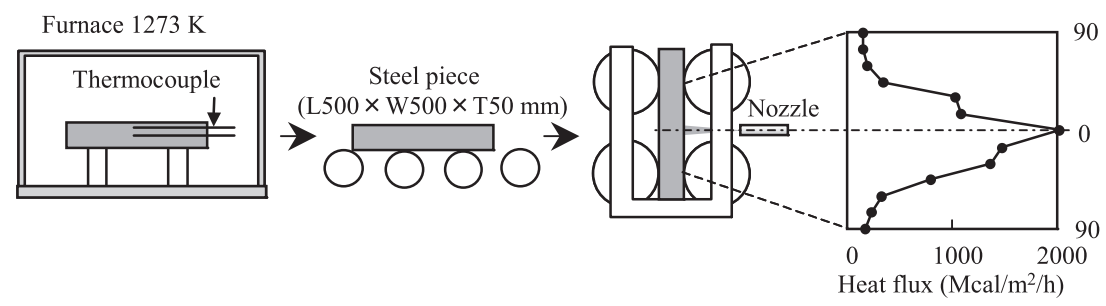

Fig. 5. Schematic view of experimental procedure for measuring heat transfer coefficient.

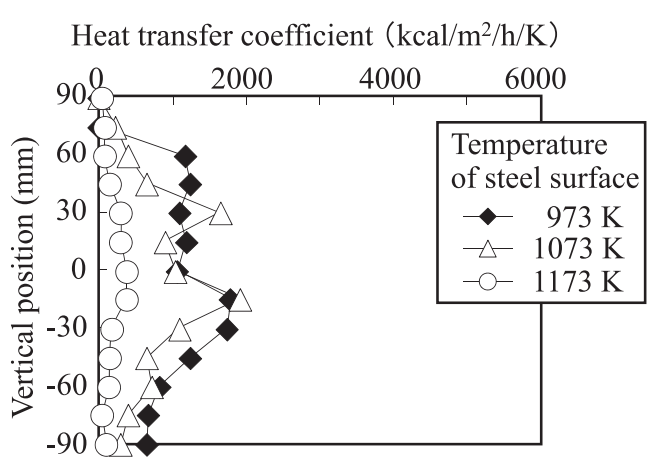

Back pressure $=\mathbf{0 . 7} \mathrm{MPa}$

Water flow rate $=\mathbf{1 6 . 0}\left(\mathrm{m}^{3} / \mathrm{h}\right) / \mathrm{m}^{2}$

Fig. 6. Vertical distribution of heat transfer coefficient on flat spray nozzle (Nozzle A).

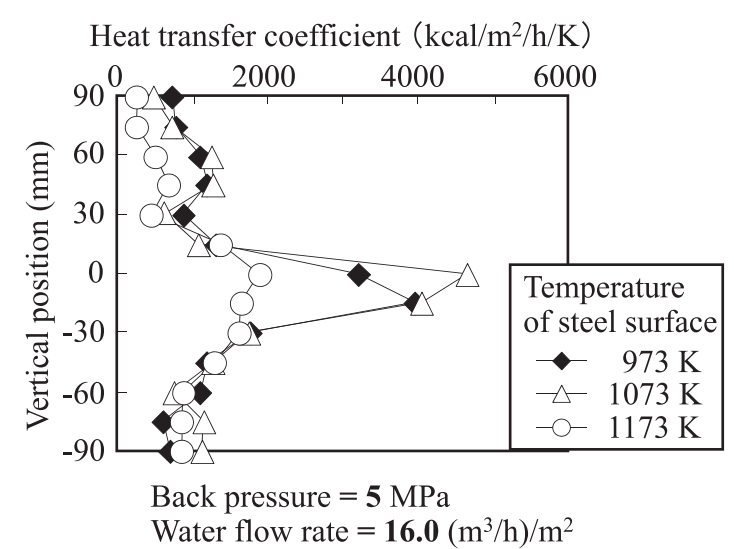

Fig. 7. Vertical distribution of heat transfer coefficient on highpressure water spray (Nozzle B). 


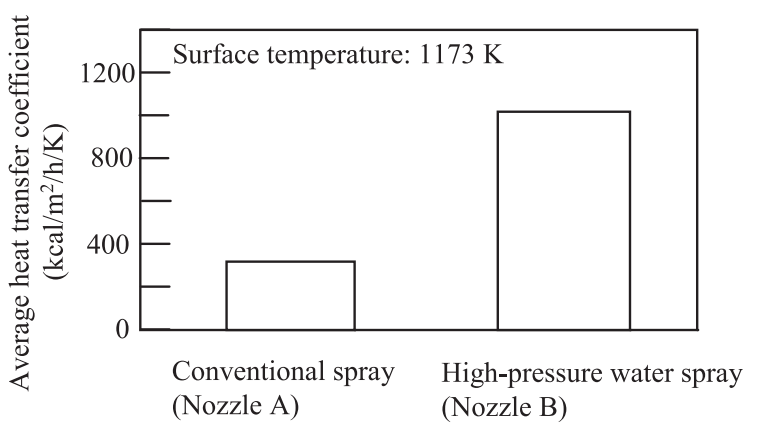

Fig. 8. Comparison of average heat transfer coefficient between conventional spray and high-pressure water spray.

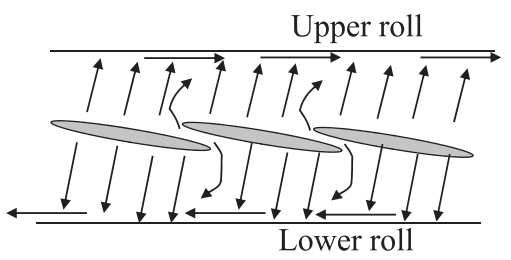

Schematic of reflected water jet

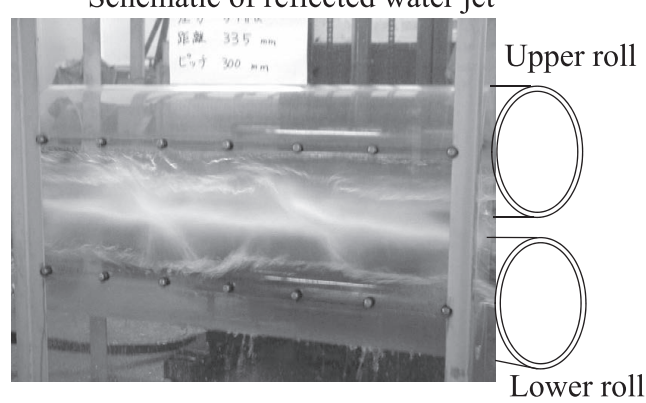

Fig. 9. Water flow between upper and lower rolls.

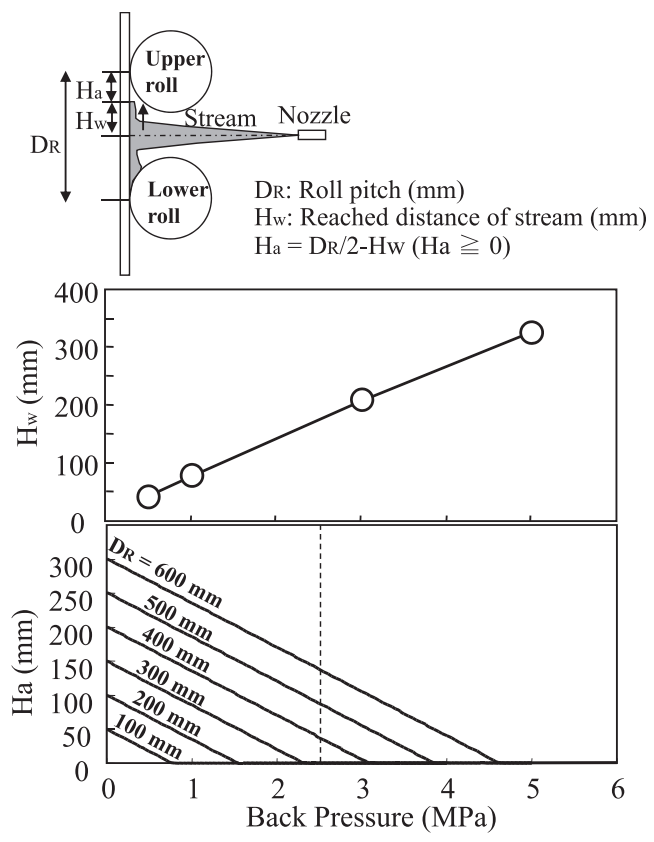

Fig. 10. Relationship between reached distance of stream and back pressure (Nozzle B).

\section{Plant Tests of High-pressure Water Spray}

\subsection{Experimental Equipment}

The new cooling system using high-pressure water spray
Table 2. Specifications of Kurashiki No. 2 CCM.

\begin{tabular}{lc}
\hline Start of operation & Jan. 1971 \\
Number of strands & 2 \\
Machine type & Bow type \\
Casting radius & $12.5 \mathrm{~m}$ \\
Size of cast steel & Thickness: $215 \mathrm{~mm}$ \\
Width: $850-1500 \mathrm{~mm}$ \\
Maching speed & $0.75-1.25 \mathrm{~m} / \mathrm{min}$ \\
\hline
\end{tabular}

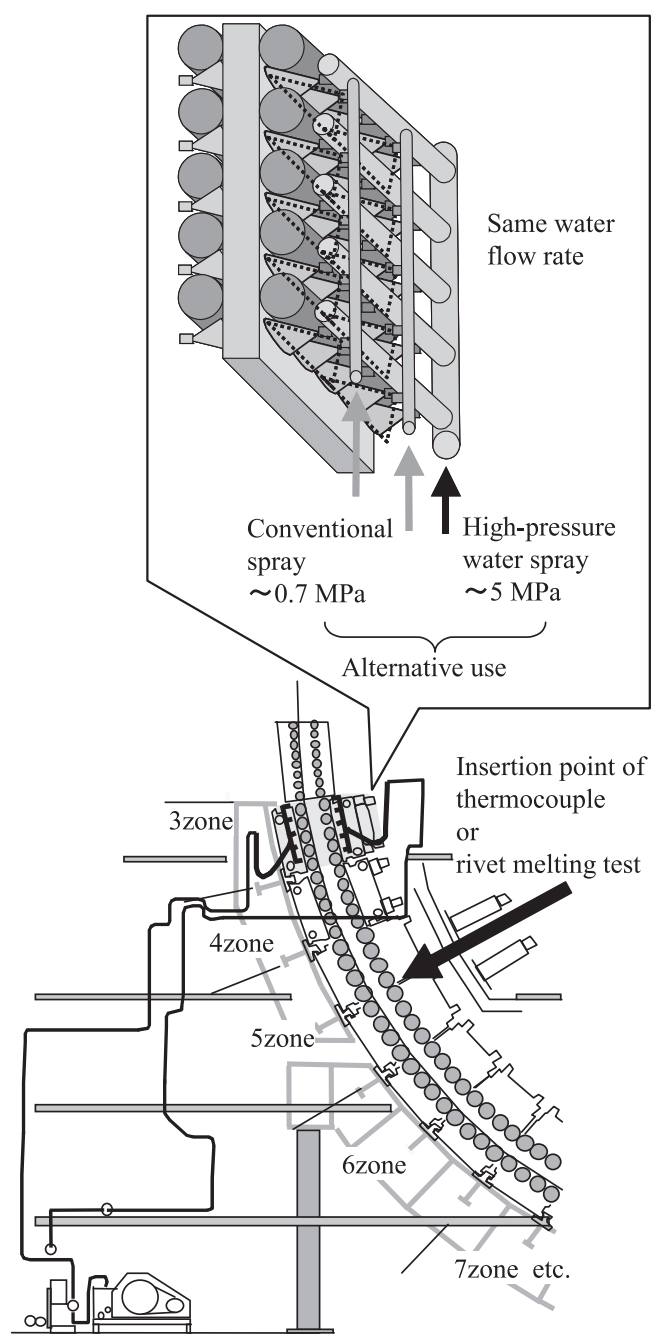

Fig. 11. Schematic of experimental equipment for high-pressure water spray.

was tested at the Kurashiki No. 2 continuous slab caster. Table 2 shows the main specifications of the No. 2 CC. The high-pressure water spray was installed in the No. 3 cooling zone at the No. 1 strand. Both the conventional spray and high-pressure water spray had one segment and the experiments could be carried out without exchanging the segment. The new cooling device used for the experiments is shown in Fig. 11. Plumbing fixtures for the high-pressure water spray were laid in addition to conventional fixtures, and either the conventional spray or the high-pressure water spray was used alternatively.

High-pressure water was supplied by two plunger pumps for the loose and fixed side of the slab, which were installed 


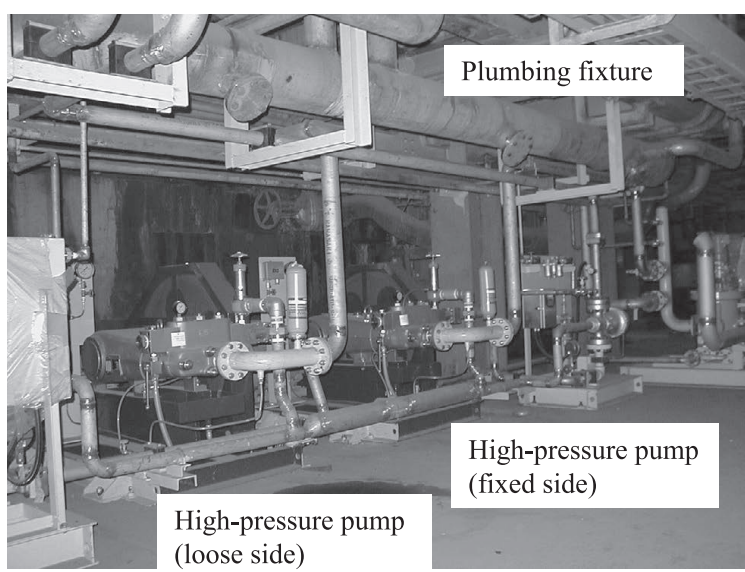

Fig. 12. Equipment for high-pressure water supply.

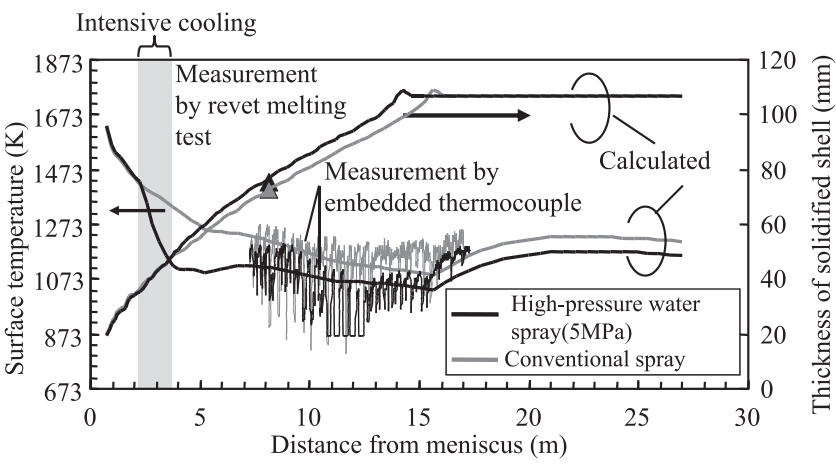

Fig. 13. Measured and calculated results of surface temperature and solidified shell thickness (casting velocity: $0.9 \mathrm{~m} / \mathrm{min}$ ).

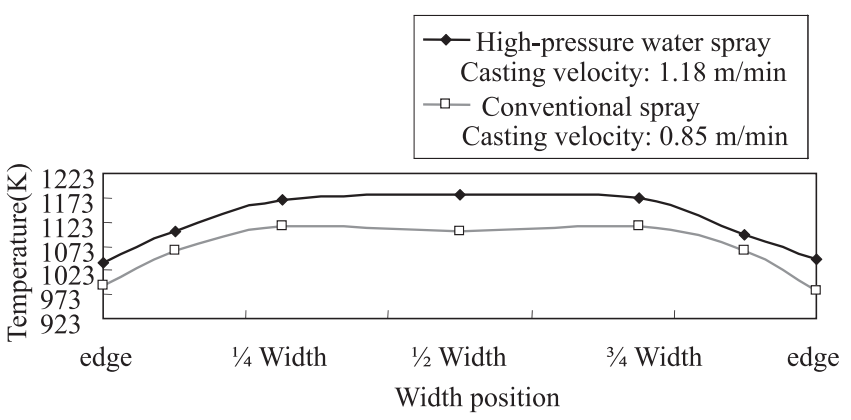

Fig. 14. Distributions of slab surface temperature at machine outlet position.

at ground level as shown in Fig. 12. The experiments were carried out at the same water flow rate. The flow rate of high-pressure water was controlled by the pump output (pump revolution speed) such that the actual flow rate matched the setting value.

\subsection{Results of Plant Tests}

Actual plant tests were carried for several grades of steel. The results for medium-carbon steel, which is particularly sensitive to surface and inner cracking, were as follows.

\subsubsection{Improvement of Casting Velocity}

Operational problems such as mold level hunching and breakout did not occur in any of the trials using the highpressure water spray. For medium carbon steels, it was con-
Table 3. Solidification constant and average heat transfer coefficient calculated by a mathematical model.

\begin{tabular}{lcccc}
\hline & $\begin{array}{l}\text { Casting } \\
\text { velocity } \\
(\mathrm{m} / \mathrm{min})\end{array}$ & $\begin{array}{l}\mathrm{K} \text { factor } \\
\left(\mathrm{mm} / \mathrm{min}^{-0.5}\right)\end{array}$ & $\begin{array}{l}\text { Metallurgical } \\
\text { length }(\mathrm{m})\end{array}$ & $\begin{array}{l}\text { Average heat } \\
\text { transfer coefficient } \\
\left(\mathrm{kcal} / \mathrm{m}^{2} / \mathrm{h} / \mathrm{K}\right)\end{array}$ \\
\hline $\begin{array}{l}\text { Conventional } \\
\text { spray }\end{array}$ & 0.9 & 27.4 & 16.15 & 422 \\
$\begin{array}{l}\text { High-pressure } \\
\text { water spray }\end{array}$ & 0.9 & 28.6 & 14.62 & 1193 \\
$\begin{array}{l}\text { High-pressure } \\
\text { water spray }\end{array}$ & 1.18 & 29.05 & 16.155 & 1162 \\
\hline
\end{tabular}

firmed that casting speed was increased by $30 \%$ without causing problems in operation or slab quality.

Casting velocity: $0.9 \mathrm{~m} / \mathrm{min} \rightarrow 1.18 \mathrm{~m} / \mathrm{min}$

4.2.2. Surface Temperature, Solidified Shell Thickness and Cooling Capacity during Casting

In order to evaluate the cooling intensity during casting, the following were measured:

- Strand surface temperature by embedded thermocouple in the strand (7.5 m below meniscus).

- Solidified shell thickness by revet melting test (pin shooting method) (7.5 m below meniscus).

- Strand surface temperature by a pyrometer (machine outlet position).

Representative measurements of surface temperature and solidified shell thickness at the casting speed of $0.9 \mathrm{~m} / \mathrm{min}$ are shown in Fig. 13. Thermal calculations by a mathematical model are superimposed on the figure. The temperature of the high-pressure water spray was $70 \mathrm{~K}$ below that of the conventional spray at $7.5 \mathrm{~m}$ below meniscus.

The distributions of temperature in the width direction at the machine outlet position are shown in Fig. 14. The straightening point of the caster is located outside of the secondary cooling zone at $20 \mathrm{~m}$ below meniscus. At the straightening position, the temperature recovery was observed owing to the mild radiation cooling by atmospheric air. It was confirmed that the difference in temperature between the high-pressure water spray and conventional spray was very small and uniform cooling was achieved.

Solidification constant ( $\mathrm{K}$ factor), metallurgical length and heat transfer coefficient at the No. 3 cooling zone are summarized in Table 3. The heat transfer coefficients estimated by thermal calculation agreed closely with the heat transfer coefficient data measured in the laboratory. The metallurgical length for the high-pressure spray at the casting speed of $1.18 \mathrm{~m} / \mathrm{min}$ is almost the same value as that for the conventional spray at the casting speed of $0.9 \mathrm{~m} / \mathrm{min}$. Thus, hard cooling can be achieved by the high-pressure water spray.

\subsubsection{Slab Quality}

Surface defects such as transverse cracks and longitudinal cracks did not occur in any of the trials using the high-pressure water spray. The temperature from the straightening point to the machine outlet position was around $1173 \mathrm{~K}$. The ductile temperature investigated by the in-situ hot tensile tests for the medium carbon steels was in the range of 973 $\mathrm{K}$ and $1073 \mathrm{~K}$. It is considered that the ductile temperature 


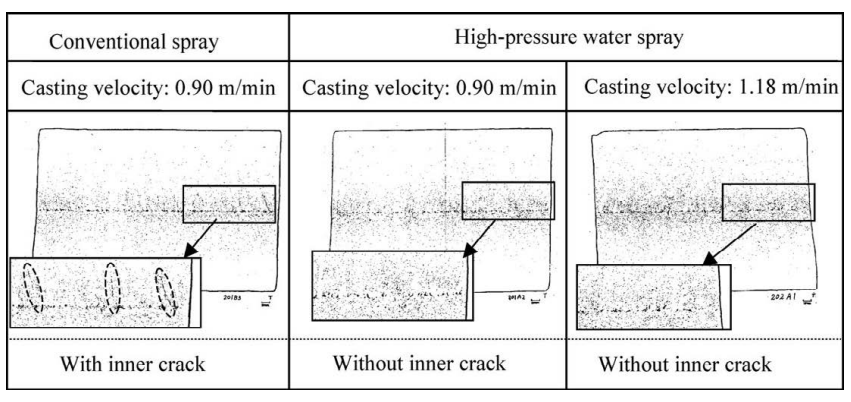

Fig. 15. Comparison of occurrence of inner crack (sulfur print, longitudinal cross section).

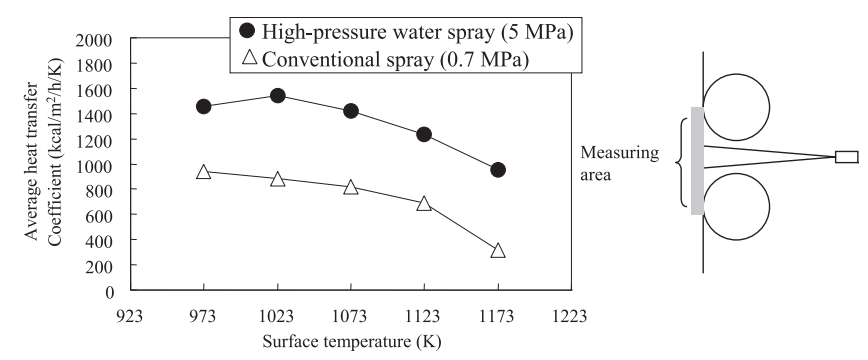

Fig. 16. Comparison of average heat transfer coefficient between conventional spray and high-pressure water spray.

at the straightening point was avoided owing to temperature recovery after intensive cooling.

Figure 15 shows the microstructure of a slab sample. Although slight inner cracks were observed for the conventional spray, there were no inner cracks for the high pressure water spray at the casting speed of 0.9 and $1.18 \mathrm{~m} / \mathrm{min}$. Bulging strain appeared to be reduced by the high-pressure water spray, thus preventing inner cracks.

\section{Discussion}

The mechanism of intensive cooling by the high-pressure water spray is as follows. The relationship between surface temperature and heat transfer coefficient is shown in Fig. 16. Note that the heat transfer coefficient at $1173 \mathrm{~K}$ for the high-pressure water spray is especially larger than for the conventional spray. It is considered that the momentum derived from the high-pressure water helped to destroy and renew the vapor film in the film boiling region. Leidenfrost temperature results in over $1173 \mathrm{~K}$ for high-water pressure spray at water pressure of $5 \mathrm{MPa}$, but it is around $873 \mathrm{~K}$ for the conventional spray. It is thought that nucleate boiling regime on a cooling curve is dominant by the increase in the Leidenfrost temperature and the heat transfer coefficient is rapidly increased. The high-pressure water spray may be most effective when installed at the location where the slab surface temperature is high, corresponding to the mold outlet or bending. The relationship between surface temperature and heat transfer coefficient below the upper roll is shown in Fig. 17. Although a constant heat transfer coefficient of $200 \mathrm{kcal} / \mathrm{m}^{2} / \mathrm{h} / \mathrm{K}$ was obtained for the conventional spray, a large heat transfer coefficient of approximately $200-1000 \mathrm{kcal} / \mathrm{m}^{2} / \mathrm{h} / \mathrm{K}$ was achieved for the high-pressure water spray. This value is close to the average heat transfer coefficient of the conventional spray, probably because the

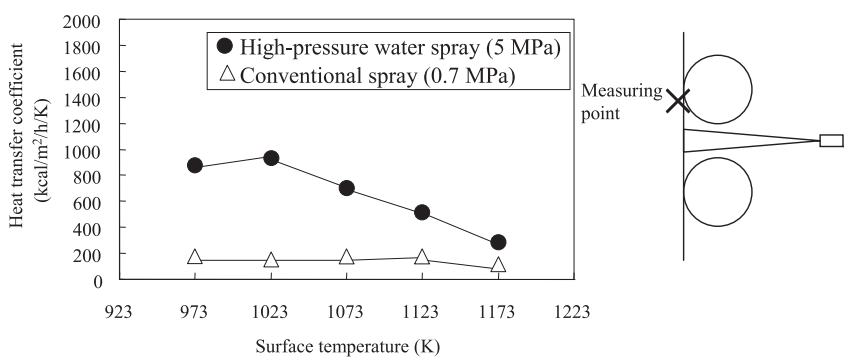

Fig. 17. Comparison of heat transfer coefficient close to upper roll between conventional spray and high-pressure water spray.

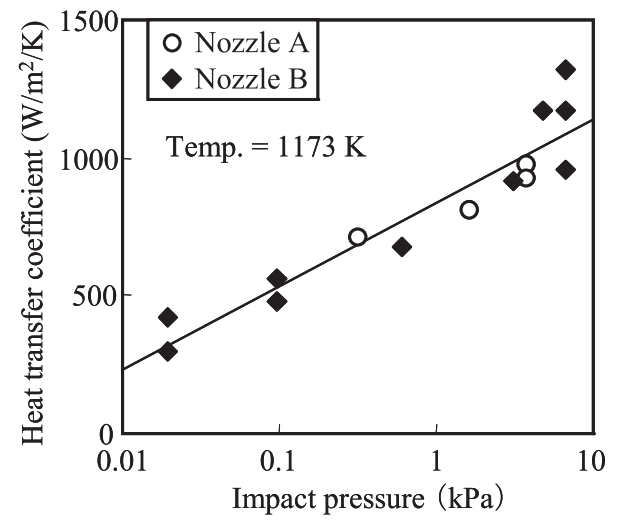

Fig. 18. Effect of water pressure on heat transfer coefficient.

reflected spray jet reached the regime cooled by atmospheric air below the upper roll.

In a previous study, Wada et al. proposed the following equation for impact pressure: ${ }^{15,16)}$

$$
\mathrm{P}^{\prime}=5.64 \times \mathrm{P} \times \mathrm{Qn} / \mathrm{H}^{2}
$$

where, P': impact pressure (MPa), P: delivery pressure $(\mathrm{MPa}), \mathrm{Qn}$ : water flow rate $(1 / \mathrm{sec})$, and $\mathrm{H}$ : distance between nozzle and cooling surface $(\mathrm{cm})$.

Although Eq. (1) is estimated using the de-scaling nozzles and the spray width angle is not considered, the impact pressure is calculated by the equation because the spray width angle used in this research is similar to the previous one. This relationship between the heat transfer coefficient and impact pressure is shown in Fig. 18, which reveals a linear correlation. It was found that the impact pressure of highpressure water spray is larger than the pressure for forming the vapor film and the thickness of the vapor film is reduced as a result.

Hence, the relationship with the heat transfer coefficient given by Eq. (1) and thermal calculations containing heat transfer and solidification makes it possible to predict the optimum cooling system for actual plant trials.

\section{Conclusions}

In order to apply high-pressure water spray cooling to secondary cooling in continuous casting, a systematic study of spray cooling using a conventional flat spray and highpressure water spray was conducted in laboratory-scale experiments and plant tests. The results obtained in this work are summarized as follows: 
(1) The average heat transfer coefficient at a hydraulic pressure of $5 \mathrm{MPa}$ was 2.8 times larger than that of a conventional water spray nozzle at the same water flow rate.

(2) The casting speed was increased by $30 \%$ without any inner cracks and surface cracks when using the highpressure water spray.

\section{REFERENCES}

1) S. Nanbu, H. Uehara, H. Yamasaki, K. Oshima, S. Nakajima and K. Nanba: CAMP-ISIJ, 15 (2002), 167.

2) M. Mitsuzuka, Y. Fukuhisa, M. Wake, M. Okajima, N. Miyashita and Y. Takeda: Tetsu-to-Hagané, 70 (1984), No. 9, 76.

3) M. Raudensky and J. Horsky: Ironmaking Steelmaking, 32 (2005), 159.

4) S. Nishio and K. Hirata: Trans. Jpn. Soc. Mech. Eng., 44 (1978), No.380, 1335

5) S. Kubori and N. Kaguchi: AISTech 2010 Proc., 2, AIST, Pittsburgh, USA, (2010), 93.
6) T. Teshima, T. Kitagawa, S. Miyahara, H. Funanokawa, K. Ozawa and K. Okimoto: Tetsu-to-Hagané, 74 (1988), No.7, 1282.

7) M. Shimada and M. Mitsuzuka: Tetsu-to-Hagané, 52 (1966), 1643.

8) K. Sasaki, Y. Sugitani and M. Kawasaki: Tetsu-to-Hagané, 65 (1979), No.1, 90.

9) T. Nozaki, J. Matsuno, K. Murata, H. Ooi and K. Kodama: Trans. Iron Steel Inst. Jpn., 18 (1978), No.6, 330.

10) B. Barber, B. Patrick, P. Watson, P. York, F. Kitching, H. Sha, K. Klaushaar and K. H. Spitzer: Revue de Metallurgie-CIT, 92 (1996), 1403.

11) A.Yamauchi and K. Sorimachi: CAMP-ISIJ, 7 (1994), 278.

12) Y. Ito, T. Murai, M. Abe and Y. Miki: Asia Steel 2006 Proc., ISIJ, Tokyo, Japan, (2006), 978.

13) T. Kawano, K. Shima, T. Kuwabara, T. Yamamoto, M. Wake and S. Tsuneoka: Tetsu-to-Hagané, 68 (1982), 1792.

14) U. Reiners, R. Jeschar, R.Schloz, D. Zebrowski and W. Reichelt: Steel Research, 56 (1985), No. 5, 239.

15) T. Wada, M. Ueda and M. Oshimi: Tetsu-to-Hagané, 77 (1991), No. 9, 1450 .

16) T. Wada, M. Oshimi and M. Ueda: Tetsu-to-Hagané, 77 (1991), No. 9,1458 . 